\title{
Article
}

\section{Aligning the talent pathway: Exploring the role and mechanisms of coherence in development}

\author{
Webb, Vincent, Collins, David John and Cruickshank, Andrew \\ Available at http://clok.uclan.ac.uk/14062/ \\ Webb, Vincent, Collins, David John ORCID: 0000-0002-7601-0454 and \\ Cruickshank, Andrew ORCID: 0000-0002-8893-2341 (2016) Aligning the talent \\ pathway: Exploring the role and mechanisms of coherence in development. \\ Journal of Sports Sciences, 34 (19). pp. 1799-1807. ISSN 0264-0414
}

It is advisable to refer to the publisher's version if you intend to cite from the work. http://dx.doi.org/10.1080/02640414.2016.1139162

For more information about UCLan's research in this area go to http://www.uclan.ac.uk/researchgroups/ and search for < name of research Group>.

For information about Research generally at UCLan please go to http://www.uclan.ac.uk/research/

All outputs in CLoK are protected by Intellectual Property Rights law, including Copyright law. Copyright, IPR and Moral Rights for the works on this site are retained by the individual authors and/or other copyright owners. Terms and conditions for use of this material are defined in the policies page.

\section{CLoK}

Central Lancashire online Knowledge www.clok.uclan.ac.uk

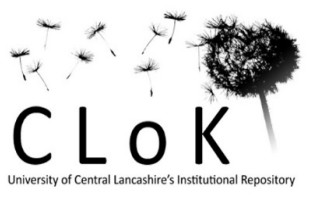


This is a pre-proof corrected manuscript, as accepted for publication, of an article published by Taylor \& Francis in Journal of Sports Sciences on $20^{\text {th }}$ January 2016, available online at:

http://www.tandfonline.com/doi/full/10.1080/02640414.2016.1139162\#.VzsQ6vkrJD8

\section{Aligning the talent pathway: exploring the role and mechanisms of coherence in} development VINCENT WEBB $^{1,2}$, DAVE COLLINS ${ }^{2,3}$ \& ANDREW CRUICKSHANK ${ }^{2,3}$ ${ }^{1}$ British Cycling, Manchester, UK, ${ }^{2}$ Institute of Coaching and Performance, University of Central Lancashire, Preston, UK and ${ }^{3}$ Grey Matters for Performance Ltd, Stratfordupon-Avon, $U K$ 
Webb et al.

\begin{abstract}
Although our understanding of psychological and social factors in talent development continues to expand, knowledge of the broader system that underpins entire talent pathways is relatively limited. Indeed, little work has moved beyond the recognition that coherence in this system is important to consider how this may be achieved; particularly in relation to coherent coaching. As such, the aim of this paper was to address gaps in talent development and coaching literature and explore principles and potential mechanisms of coherent coaching in sport organisations' talent pathways. After defining and contextualising coherence in whole talent pathways, including barriers to attainment, we discuss how an understanding of coach epistemology can provide a basis for integrating personal and collective coach coherence and therefore a coherent performer experience. With epistemology as our focal point, we then consider how coherent coaching may be supported through the strategic recruitment and placement of coaches, complimentary coach education and development and the use of change agents who can set and shape the coaching milieu, facilitate cross-level communication and enable epistemology-focused reflection and evaluation. Finally, we conclude with some brief recommendations for advancing practically-meaningful knowledge in this important area.
\end{abstract}

Keywords: talent development, pathway management, coach management, epistemology, change agents 


\section{Introduction}

As the importance of talent development continues to be stressed, an expanding network of factors has been explored. The unit of analysis in most work to date has, logically, been the individual performer; in doing so, improving our understanding of a range of relevant attributes, skills and coaching needs (e.g., Collins \& MacNamara, 2012;

Durand-Bush \& Salmela, 2001; MacNamara, Button, \& Collins, 2010a, 2010b). Conversely, our understanding of the broader system that underpins most talent pathways is still limited. Indeed, while coherence is a characteristic of effective talent pathways (Martindale, Abraham, \& Collins, 2007), represented by inputs that are structured, complementary, and framed against long-term agendas, our knowledge on how this may be achieved is underdeveloped; particularly with regard to the coaching goals, methods and styles that performers are progressively exposed to. Based on current research and our experience of leading/supporting coaching systems and talent pathways, this paper therefore explores the principles of coherent talent pathways and how coaching systems can be managed for their realisation.

It is now widely accepted that talent development is a non-linear, dynamic and complex process (Abbott, Button, Pepping \& Collins, 2005; Phillips, Davids, Renshaw \& Portus, 2010; Simonton, 2001). As such, a growing body of work now exists on the individual characteristics and skills that help performers to negotiate the "rocky road" to senior performance (Collins \& MacNamara, 2012; Crust \& Clough, 2011; Petitpas, Champagne, Chartrand, Danish, \& Murphy, 1997). In addition to performer-oriented features, researchers have also emphasised a number of relevant external factors (e.g., 
Webb et al.

family and social support: Côté, 1999; Stambulova, Franck, \& Weibull, 2012).

Supported by recent research (Morris, Tod, \& Oliver, 2015), one of the most influential of these externals factors is the organisational and coaching environment where development occurs.

In this regard, Martindale et al. (2007) identified five general principles of effective talent development environments. Specifically, these were: long term aims and methods that are systematically planned and implemented; coherent support networks and messages; emphasis on appropriate development over early success; individualised and on-going development; and an integrated, holistic and systematic overall approach (that covers the previous four factors). To date, however, little work has explored how each of these factors can be optimised; including that on coherent support networks and messages from first contact to senior performance. As the group who primarily "deliver" talent pathways, a logical progression would see attention turn to surrounding coaching systems. Unfortunately, however, little is known (at least empirically) on how an entire set of coaches in one organisation can best deliver desired outputs (e.g., adaptable, independent and resilient senior performers), outcomes (e.g., medals or participation) and process markers (e.g., coherent athlete experience) through complementary action. Indeed, we are not aware of any work that has specifically considered this important issue to date.

Given the aforementioned gaps in talent development and coaching literature, the aim of this paper is to critically explore principles and mechanisms of coherent coaching in the context of sport organisations' talent pathways. Given general similarities in the talent development process in different settings, as well as our aim to explore general 
principles and mechanisms of talent pathways in this opening foray, we do not refer to one type of sport or organisation in particular (e.g., team or individual sport; Olympic or professional sport). Additionally, by "talent pathways" we refer to programmes that are designed to select and support performers with potential to reach senior level. While performers clearly enter (and re-enter) pathways at different ages and stages, for purposes of clarity in this paper we consider pathway coherence from the earliest possible point of entry all the way to senior-level transition. For similar reasons, broader issues such as sampling and specialisation are also not addressed; however, we ask the reader to keep in mind that performers may be on multiple pathways at the same time, or sampling other sports on a recreational level (this added complexity, we suggest, requires specific consideration in other work). Finally, our approach is built upon a fundamentally pragmatic perspective (Giacobbi, Poczwardowski, Hager, 2005); leading us to combine our applied experience with pertinent literature in attempt to trigger the development of practically-meaningful and theoretically-grounded knowledge in an important applied area.

Returning to the specific aim of this paper (to critically explore principles and mechanisms of coherent coaching in talent pathways), our discussion is presented in three main parts. First, we consider some key markers of coherent talent pathways, including coaching-specific markers and common "derailers" of coherent coach action (and thus coherent talent pathways). Building on this foundation, we then discuss how an understanding of personal epistemology may help coach managers to optimise the coherence of their coaching system and, ultimately, performer experience. To conclude, we offer some initial advice for such managers as they aim to align the coaching system 
Webb et al.

and support their organisation's desired outcomes and outputs, plus outline some next steps for researchers looking to develop empirically-based knowledge in this important area. All considerations in this work were approved by the authors' institutional ethics committee.

\section{Coherent talent pathways: what do they look like?}

To counter the common complaint from senior performance leaders and coaches that performers are often "not ready" for the top level when they arrive at the end of the junior/transition program (Larsen, Alfermann, Henriksen, \& Christiansen, 2013), coherent pathways should be underpinned a clear definition and understanding of the "typical" performer that the sport aims to produce. Moreover, they should also be underpinned by a clear definition and understanding of the "typical" performer that should be developing at each specific phase of their pathway. Of course, the desired "end product" will clearly vary across different environments; as shaped by the nature of typical progression (e.g., the typical number of development years to reach senior level), the sport's stability (e.g., the rate of rule changes), the organisation's internal consistency (e.g., the extent to which strategic/performance directions change) and its' wider socio-political and financial challenges (e.g., balance of performance/development/participation agendas; reliability of funding). Regardless, however, our main point is that optimal systems will be locked into (and proactively use) their surrounding contexts (Henriksen, Stambulova, \& Roessler, 2010a, 2010b, 2011). For example, when peak performance tends to arrive at a young age (e.g., 
gymnastics), or in a team with a deep-rooted culture and playing style, it might make sense to develop individuals through a highly focused program that helps them to perform in a specific manner. In such a system, performers may therefore face similar types of coaches, take part in similar types of training centres/environments, be exposed to similar types of coaching methods and sports medicine/science support and face similar types of structured challenge as they progress up the pathway. Performers who reach the end of such a route will have tended to advance quickly and be able to perform in a very specific or "the team X" way but, we suggest, be somewhat fragile and struggle to cope and adjust when the "goal posts shift" or novel challenges are faced; for example, adapting to a new style of performing in response to opponents or injury (cf. Collins \& MacNamara, 2012; Debois, Ledon, \& Wyellman, 2015; Henriksen \& Mortensen, 2014). This pathway is depicted in Figure 1.

Alternatively, when peak performance tends to be achieved relatively later (e.g., rugby) or in organisations where management structures regularly change (e.g., football) then it might be sensible to develop individuals who are more adaptable and resilient to dynamic contexts. Here, performers will engage with noticeably different coaches, participate in different types of training centres/environments and be exposed to lots of different coaching methods and sports medicine/science support. In contrast to those on the straight and narrow pathway (Figure 1), performers will have to almost propel themselves upwards while they are "ping-ponged" by the high levels of variation and unpredictability. To be clear, this ability to self-propel will not just be based on resilience (Sarkar, Fletcher, \& Brown, 2015) but rather a host of psychological characteristics of developing excellence (MacNamara et al., 2010a, 2010b). Indeed, the 
Webb et al.

performer's rate of progress may be somewhat limited unless the individual is particularly determined and adept at skills such as goal setting, commitment, coping and reflection (Bruner, Munroe-Chandler, \& Spink, 2008; Finn \& McKenna, 2010; MacNamara et al., 2010a, 2010b; Pummell, Harwood, \& Lavallee, 2008; Stambulova, 2009). This pathway is depicted in Figure 2.

Given the limits of the pathways in Figures 1 and 2 (i.e., the speed at which performers can be developed for senior competition against their ultimate level of adaptability, independence and resilience), as well as the unlikely need for either extreme, an optimal blend may be one where performers reach senior level in a sportspecific timely fashion but with the required levels of independence, adaptability and resilience. In such a "goldilocks" system, performers will engage with different types of coaches but not too different, participate in different training centre's/environments but not too different, be exposed to different coaching methods and sports medicine/science support but not too different and face different challenges but not too different. Accordingly, performers will not ping-pong too much (and run a higher risk of progressing slowly) or fail to ping-pong at all (and run a higher risk of developing insufficient independence, adaptability, or resilience); in short, things will be "just right"! This pathway is depicted in Figure 3.

To be clear, our point is not that every sport should work to the same parameters; rather, that variability throughout the pathway should be tailored to the exact nature of the organisation, its surrounding contexts and the challenge faced. A coherent system will therefore be based upon a clearly defined and well-planned "bandwidth" of variability that fits the organisation's contexts and long-term objectives (see the dashed 
vertical lines running through the pathway in Figure 3). Moreover, it will also be reflected by the provision of variability (e.g., different coach methods or challenges) at the most apt time. Performers will therefore be coherently "pinged" or "ponged" (i.e., provided the most suitable focus or challenge) at general phases of their development and also at specific points within these phases. Importantly, this focus or challenge will be tailored to the individual's characteristics, needs, and long-term development plan for optimal impact (Martindale et al., 2007).

\section{Coaching-specific markers of coherence}

Regardless of the necessary level of "just right-ness", coherence in talent pathways will be characterised by logical, intentional, progressive and (where appropriate) consistently applied coaching methods. These methods will be complimentary (rather than identical), adaptive (rather than resistant) to changing demands/challenges and specifically designed and combined in an age and stage-appropriate manner (cf. Bailey, Collins, Ford, MacNamara, Toms, \& Pearce, 2010). Accordingly, all work in the training environment will align with the system's objectives for a specific development phase and "lock into" what has come before (e.g., the previous age-group/level) and what will come next for the performer (e.g., the next age-group/level).

At the micro level, coherent pathways will also be characterised by consistency in the perceptions and behaviours of the coach and performer; in short, both will understand what goals they are working towards, how and why they are doing what they are doing to achieve these. This does not necessarily mean that coaches and performers 
Webb et al.

(or coaches and coaches) must "like" each other; rather, a shared mental model of what is to be done and achieved at each relevant age and phase is prioritised. Additionally, this coherence will inevitably be reliant, at least to some degree, on the coherence between coaches and parents/guardians; especially during earlier phases of performer development. Indeed, Smoll, Cumming and Smith (2011) suggest that this "triad" behave and interact in complex ways and, as such, can create contrasting views on what are appropriate, rewarding and progressive activities (cf. Harwood \& Knight 2009; Hein \& Jõesarr, 2014; Pankhurst, Collins, \& MacNamara, 2013); which can of course have serious implications on the development of the confused performer.

If it were only that easy: common challenges to (and derailers of) coaching coherence

While we have identified some key features of coherent pathways, achieving these are much (much!) easier said than done. Certainly, a plethora of factors can challenge and derail coherence, including that across the organisation's body of coaches (please note that the features that follow are also relevant to other support staff groups). At the macro level, organisations that do not have a clear definition of the goals that they want to achieve and the type of performers that they need to produce will provide arguably irreversible issues for coach coherence (Larsen et al., 2013). Mismatches between the philosophies and objectives of management agencies (e.g., Boards of Directors vs. funding groups) will also pose major issues (cf. Cruickshank et al., 2014, 2015. For example, the ability of coaches to work on significant and innovative long-term plans in many Olympic sports is constrained by funders' results-based (i.e., medals and 
participation) allocation and a strong encouragement to follow other sports' "proven" best practice (Sam, 2012).

At the micro-level, the extent of coherence can be compromised by coaches not having a clear understanding (or perhaps a desire to understand) their general and specific role in the "big picture" (cf. Nash, Sproule, \& Horton, 2008). Problems may also be faced if the overall skill-set of coaches is not sufficiently complimentary, balanced, or able to provide necessary learning opportunities and challenges (i.e., those which can deliver the right ping or pong at the right time) (Martindale \& Mortimer, 2011; Persson, 2011). Similarly, issues may also be likely to arise when individuals do not have the adaptability to handle the incessant variation in their environment, or the insight and professionalism to engage with critical debate around performer pingponging (Collins, Abraham, \& Collins, 2012; Kahneman \& Klein, 2009). Personal motivations and self-interest can also pose a major problem. Certainly, the threat and impact of coach/staff politics on collective action has been well documented (e.g., Cruickshank et al., 2014, 2015; Potrac \& Jones, 2009; Thompson, Potrac, \& Jones, 2013). Although a positive feature if appropriately harnessed, the consequent potential for a "my athlete/team, my success" approach will, in most cases, be a major barrier to coach and system coherence (cf. Cruickshank et al., 2014). All in all, the challenges listed here, which are indicative rather than extensive, are more likely to lead to pathways that provide a performer experience like the example shown in Figure 4.

\section{Promoting and protecting coach coherence: using personal epistemology as a mechanism for goldilocks pathways}


Webb et al.

Based on the preceding section, it would seem crucial that talent pathways establish and work with a shared ideology of coaching practice. This does not mean that all coaches share the same fundamental approach; rather, coherence will be reflected in a "philosophical bandwidth" that: a) facilitates the desired levels of adaptability, independence and resilience in performers; b) offers resistance to damaging rhetoric, politics, or personal agendas; and c) is understood and followed by all coaches (see the dashed lines in Figure 3 for reference). Achieving this outcome clearly requires a management system that continually defines the general and specific aims of coaching throughout the pathway. Equally, success will also depend on coaches having a deep awareness of their guiding (or desired) values and beliefs and how these align with/complement their peers and goals of the pathway. It is on this latter area-defined as personal epistemology - which we consider in this section. Indeed, beyond enabling internal coherence (i.e., the alignment of one's philosophy with actual practice), it also appears to provide the basis for a lingua franca that could aid coherence and integration across individuals, groups and entire talent pathways (cf. Grecic \& Collins, 2012, 2013).

\section{Personal epistemology}

Epistemology is the branch of philosophy that is concerned with the nature and scope of knowledge and the processes of knowing and learning. Shaping our view on what knowledge is and how it can be acquired, our epistemology is thereby fundamental to how we perceive, think, make decisions and act. Maturing to varying levels based on 
age, life experiences, education and sociocultural influences, epistemology is a multidimensional construct (cf. Chan \& Elliot, 2000; Schommer, 1990, 1994; Youn, Yang, \& Choi, 2001). Specifically, Schommer (1990, 2002) argued for four types of epistemological beliefs. These are one's belief about: the stability of knowledge (ranging from knowledge being certain to tentative); the structure of knowledge (ranging from knowledge being organised as isolated facts to integrated concepts); the control of learning (ranging from learning being genetically determined to enhanced via education and experience); and the speed of learning (ranging from learning being quick, as based on inherent abilities, to gradual). As each belief is more complex than these dichotomies may suggest (e.g., certain vs. uncertain knowledge), Schommer (1994) later argued that they should be viewed as an overall distribution and not on one continuum (i.e., all four types of belief do not have to be at the same level of sophistication and can be at various stages of transition).

Applying epistemology in sport, Grecic and Collins (2013) recently argued for the use of this construct in researching and developing coaches. More specifically, these authors outlined how personal epistemology could be used as a lens for coaches to explore and assess the philosophical underpinnings of their decisions and actions, including the type of environment they create, the relationships they build, the goals that are set, their methods and assessments of performer development and the future directions that they pursue with these performers. Such links between core beliefs and all aspects of "live" practice have been termed the epistemological chain (hereafter EC). With work demonstrating its presence and relevance in coaching practice, the EC has therefore emerged as an evidence-based tool that can link coaching philosophy to the 
Webb et al.

interrelated decisions, behaviours and performance of individual and collective coaches (Grecic \& Collins, 2012). To further assess the value of an epistemological lens for aligning whole talent pathways, we now provide an overview of two broad types of personal epistemology.

Sophisticated epistemologies. Based on the work of Schommer (1994) and Grecic and Collins (2013), a coach with a sophisticated epistemology will consider knowledge as complex, uncertain, tentative, learned gradually through reasoning and self-constructed by the learner. This coach will therefore blend their experience and knowledge (declarative and procedural) to provide individualised support to performers in an autonomy-supportive manner (Mageau \& Vallerand, 2003). Such coaches help to address performer needs (in relation to the needs of the system) and support their development in an age-/stage-specific fashion. As such, coaching methods will be systematic, integrated and tailored to the performer's history/trajectory with particular emphasis on the balance, coherence and progression of practice. These methods will also be intentionally designed against relevant challenges - whether natural or manufactured - thus working to the "big picture" and preparing individuals for evolving demands. Performers will be actively involved in the coaching process and, for example, input/lead on goal setting and evaluation activities. Coaches with sophisticated epistemologies will also be more likely to collaborate and constructively argue with their peers; especially when evaluating the credibility and value of knowledge developed, held and shared by others (e.g., established authorities, popular/media-supported authorities and peers). Finally, effectiveness will be gauged against a host of process, performance and outcome measures that link back to the 
coach's evidence-based (and constantly monitored/adjusted) intentions and the needs of the performer/pathway.

Nä̈ve epistemologies. Alternatively, a coach with a naïve epistemology will generally believe that knowledge is simple, clear, certain, specific and unchanging. As such, knowledge resides elsewhere (e.g., established authorities, popular/mediasupported authorities and respected peers) and is handed down rather than developed via reason. It is unlikely that these coaches will have engaged in an extensive "knowledge journey" and critical reflection process; as a result, limiting their declarative and, to perhaps a lesser extent, procedural knowledge (i.e., they may know lots of drills but not much on the "why, when, how, where and who with" of their application). Similarly, naïve coaches may also be less likely to consider the "bigger picture" of performer development, including their own general and specific role within it. Typically, such coaches will convey a thirst for "gold standard" physical, technical and tactical measures with supporting methods that can be "copied and pasted". They are also likely to be coach centred, driven by work with "successful" performers, use their authority and control to dictate performer programs and deliver sessions as an instructor rather than facilitator with prescriptive and directive behaviours. Performer progress will be often modelled against the progression of those who have previously achieved higher level success, with the coach limiting athlete and parental input to sustain control. Peer debate will also usually be avoided or dismissed, especially if it doesn't support the coach's current beliefs/practices and there will also be little evaluation of the coaching process beyond crude outcome-based measurements (i.e., did the performer win/go faster/etc.). 
Webb et al.

Applying coach epistemology to the bandwidth principle

As implied above, coaches at either epistemological extreme (i.e., entirely sophisticated or entirely naïve) will generate fundamentally different environments and apply fundamentally different practices. From the systemic perspective offered in this paper, however, a sophisticated epistemology is not necessarily "better" than its naïve equivalent. Indeed, a more naïve coach may be more useful at particular moments during performer development than a sophisticated coach; for example, when a performer would benefit from more direct instruction, rapid learning and clear reinforcement of a new technique or behaviour. Similarly, a sophisticated coach with a more hands-off/experimental approach may struggle to engage with performers who prefer a "do it this way only" type approach. Although research and our experience suggest that most sports will benefit from having more "sophisticated-end" coaches (cf. Larsen, Alfermann, \& Christiansen, 2012), our point is that coherence across the entire talent pathway will be supported by a consistently applied philosophical bandwidth; not coaches who are all equally sophisticated or naïve. In line with our earlier points, and as shown in Figure 3, this bandwidth determines the limits of variation that performers will experience; something that is enabled by a detailed appreciation of when, where, how and why coaches and their environments, methods and processes will be different but not too different. Clearly this bandwidth will differ from sport to sport but, as all gain from some degree of variation, it makes sense for this to be intentionally defined, 
exploited and sustained if development is to be timely and optimal; including even the earliest of early specialisation sports!

In sum, a focus on personal epistemology appears to hold notable potential to inform the alignment of pathway coaches. Through greater understanding, articulation and development of one's beliefs about knowledge and learning, coaches can be more internally consistent (i.e., they think and act in a way that reliably reflects their values and beliefs). Crucially, it also provides a route to present an intentional and productive mixture of philosophies across the different stages of performer development. In short, a pathway in which coach philosophies and motivations are not necessarily "right or wrong" or "better or worse" but clear, consistent and congruent with the sport's and performers' ultimate objectives.

\section{Setting the bandwidth and managing the ping-pongs: defining, aligning and integrating coach epistemologies}

Having presented the case for the use of coach epistemology we now offer some initial advice for those aiming to create coherent coaching systems. Of course, these recommendations are by no means extensive and many other processes will play an inevitable role. As highlighted earlier, for example, role clarity, motivation to deliver on coaching potential and the distribution of resources by top management will clearly impact on pathway coherence. Based upon space constraints and our applied experience, we have therefore chosen to focus on some actions that would seem to lie at the heart of successful change management in this area. 
Webb et al.

Strategic recruitment and placement of coaches

Arguably one of the first steps for pathway/coach managers is to consider the recruitment and placement of coaches through an epistemological lens. Indeed, appreciation of each coach's naivety or sophistication can help to match coach beliefs and methods with the precise ping or pong that is required for a specific performer (or group of performers) to develop against desired outcomes (Grecic \& Collins, 2013). For example, when a goal is to help performers to take ownership of their development, experiment, solve problems and extend their decision making skills, then it would be wise to check that these individuals are working with more sophisticated coaches. Equally, if the goal is to instil rules, repeat skills and make quick improvements on narrow competencies, then it may be wise to use coaches with more naïve epistemologies. For example, consider Figure 5 and Figure 6 that show how general groups of coaches plus specific allocation within these groups can generate different bandwidths and challenges. Such strategic recruitment and deployment of coaches therefore raises the idea of "specialist challenge/support" coaches on top of "specialist age-group" coaches.

Coach education and development

Against the pressures of outcome-based funding, which often fosters a mechanistic view of performers, the pursuit of coherent coaching across entire talent pathways will clearly 
require a "step change" in the education and development channels currently provided by many sports. More specifically, coaches will need to be provided with programs and resources that help them to explicitly explore, understand, articulate and develop their epistemology; including how it links and contrasts with peers, management and goals of the pathway (Grecic \& Collins, 2013). Importantly, coaches should not be encouraged to behaviourally mimic others with more desirable epistemologies but aim to comprehend, reflect on and develop their own epistemology; thus, supporting a selfdirected and system-relevant journey of learning and progression. The development of coaches with a professional judgment and decision making approach (Abraham \& Collins, 2011), irrespective of epistemological stance, should help to facilitate this.

\section{Agents of change}

As long-term change usually needs multidimensional and systematic action (e.g., Prochaska, DiClemente, \& Norcross, 1992), the use of change agents to increase the volume and quality of coach engagement with their epistemology would seem to be particularly vital. Operating in a tutor or "meta coach" type role, these agents can be tasked to instigate and sustain change through a number of possible routes; three of which are considered here.

Working through the social milieu. As a coach's preference for knowledge and learning is strongly influenced by their "community of practice" (hereafter CoP: Culver \& Trudel, 2006; Stoszkowski \& Collins, 2014), change agents would be wise to integrate formal coach education within coaches' social networks. Such an approach 
Webb et al.

would acknowledge that the social milieu surrounding a coach can shape (or, at times, indoctrinate) individuals to conform to knowledge and behaviours accepted by the group/sub-culture in which they operate (Cushion, Armour, \& Jones, 2003); something that clearly has an impact on one's behaviour, if not also philosophy. Operationally, agent-led CoPs could emphasise and reinforce coherence through regular epistemologyfocused group forums, case conferences and observations of other coaches. By grouping CoPs based on the coaches' location in the pathway and the nature of the ping or pong that the sport wishes them to provide, these experiences will also likely help individuals to understand their precise role and why they need to coach in a way that might be independent of peers, respected "seniors" and popular misconceptions of talent development. Ensuring that these agents have an acute awareness of group dynamics is therefore vital, including the ability to establish certain coaches as beacons/cultural architects (Railo, 1986) via action that is overt/direct (e.g., positive public appraisal) and covert/indirect (e.g., exposing arrogant and stubborn coaches with undesirable epistemologies).

Cross-level communication. To help coaches to see the "big picture" and adopt an "our" (not "my") performer approach, change agents could also usefully foster broad understanding of each individual's requirements at particular phases in the pathway and particular points within these phases (cf. Collins \& Collins, 2011). To achieve this outcome, facilitation of open and persistent communication within and across phases of performer development would clearly be beneficial. As a consequence, the transition of performers from one level to the next can be appropriately planned and exploited rather than left to chance or reliant on performer initiative. Such on-going discussion on what 
performers need to be capable of physically, technically and mentally to survive and thrive at the next "station" on their journey can therefore be supported.

Epistemology-focused reflections and evaluations. As another way of helping coaches to consistently engage with their epistemology, change agents can use the EC as a framework for coach reflection and evaluation (Grecic \& Collins, 2013). Indeed, as reflection is often limited by one's knowledge and understanding (Knowles, Gilbourne, Borrie, \& Nevill, 2001), an expansion of self-awareness - as facilitated by an epistemological focus - may go some way in addressing this challenge. More specifically, the EC could be used to guide "meaning making", support understanding of self and ultimately increase coach coherence and consistency with the goals of the pathway. An appreciation of epistemology may also help individuals to critically explore the "whys" and "why nots" of their practice on a deeply personal level and therefore support development of a declarative knowledge base that supports truly expert coaching (Nash, Martindale, Collins, \& Martindale, 2012). Finally,

epistemology-oriented assessments could prove another impactful route for aligning coaches through more traditional conditioning channels (i.e., those who engage at/develop on an epistemological level are recognised with progression and reward by pathway and coach managers).

\section{The next steps}

In this paper we have identified some core principles of coherent talent pathways and how coaching systems might be managed for their realisation. In doing so, we also hope 
to have prompted a shift in focus, for both researchers and practitioners, towards the interface between pathway management, coach management and talent development. Clearly, empirical investigation is now needed to authenticate and then extend on the principles and mechanisms that we have outlined. For example, "sense checking" studies where the ping-pong experience of performers who have made it/didn't make it to senior level are evaluated against coach epistemologies would be particularly informative. As an inherently applied issue, action research would also be particularly useful for advancing our knowledge on processes and mechanisms for optimising coaching coherence. Linking with one of our key recommendations, such work could track the professional preparation of change agents and then their attempts to introduce, align and integrate coach epistemologies. Once again, this would sensibly examine impact across multiple stakeholders, including coaches, performers, pathway managers, top organisation management and external barometers such as parents. Given the significance yet currently limited knowledge of pathway/coaching coherence, we hope that work on all of these lines can be delivered for the betterment of performers, coaches and organisations alike. 


\section{References}

Abbott, A., Button, C., Pepping, G-J, \& Collins, D. (2005). Unnatural selection: talent identification and development in sport. Nonlinear Dynamics, Psychology and Life Sciences, 9, 61-88.

Abraham, A., \& Collins, D. (2011). Taking the next step: new directions for coaching science. Quest, 6, 366-384.

Bailey, R. P, Collins, D., Ford, P., MacNamara, Á., Toms, M., \& Pearce, G. (2010). Participant development in sport: An academic review. Leeds: Sports Coach UK.

Bruner, M. W., Munroe-Chandler, K. J., \& Spink, K. S. (2008). Entry into elite sport: A preliminary investigation into the transition experiences of rookie athletes. Journal of Applied Sport Psychology, 20, 236-252.

Chan, K. W., \& Elliott, R. G. (2000). Exploratory study of epistemological beliefs of Hong Kong teacher education students: resolving conceptual and empirical issues. Asia-Pacific Journal of Teacher Education, 28, 225-234.

Collins, D., Abraham, A., \& Collins, R. (2012). On vampires and wolves: exposing and exploring reasons for the differential impact of coach education. International Journal of Sports Psychology, 43, 255-271.

Collins, D., \& Collins, J. (2011). Putting them together: Skill packages to optimise team/group performance. In D. Collins, A. Button, \& H. Richards (Eds.), Performance psychology (pp. 361-380). Kidlington: Elsevier.

Collins, D., \& MacNamara, Á. (2012). The rocky road to the top: why talent needs trauma. Sports Medicine, 42, 907-914.Côté, J. (1999). The influence of the 
Webb et al.

family in the development of talent in sports. The Sport Psychologist, 13, 395417.

Cruickshank, A., Collins, D., \& Minten, S. (2014). Driving and sustaining culture change in Olympic sport performance teams: A first exploration and grounded theory. Journal of Sport \& Exercise Psychology, 36, 107-120.

Cruickshank, A., Collins, D., \& Minten, S. (2015). Driving and sustaining culture change in professional sport performance teams: a grounded theory. Psychology of Sport \& Exercise, 20, 40-50.

Crust, L., \& Clough, P. J. (2011). Developing mental toughness: from research to practice. Journal of Sport Psychology in Action, 2, 21-32.

Culver, D. \& Trudel, P. (2006) Cultivating coaches' communities of practice: Developing the potential for learning through interactions. In: R. Jones (Ed.), The sports coach as educator: Reconceptualising sports coaching (pp. 97-112). London: Routledge.

Cushion, C. J., Armour, K. M., \& Jones, R. L. (2003). Coach education and continuing professional development: experience and learning to coach. Quest, 55, 215-230.

Debois, N, Ledon, A., \& Wyellman, P. (2015). A lifespan perspective on the dual career of elite male athletes. Psychology of Sport and Exercise, 21, 15-26.

Durand-Bush, N., \& Salmela, J. H. (2001). The development of talent in sport. In: R. N. Singer, H. A. Hausenblas, \& C. M. Janelle (Eds.), Handbook of sport psychology (pp. 269-289). NY: Wiley. 
Finn, J., \& McKenna, J. (2010). Coping with academy-to-first-team transitions in elite English male team sports: The coaches' perspective. International Journal of Sport Science and Coaching, 5, 257-279.

Giacobbi, P. R., Poczwardowski, A., \& Hager, P. (2005). A pragmatic research philosophy for sport and exercise psychology. The Sport Psychologist, 19, 1831.

Grecic, D., \& Collins, D. (2012). A qualitative investigation of elite golf coaches' knowledge and the epistemological chain. Journal of Qualitative Research in Sports Studies, 6, 49-70.

Grecic, D., \& Collins, D. (2013). The epistemological chain: practical applications in sports. Quest, 65, 151-168.

Harwood, C. G., \& Knight, C. J. (2009). Understanding parental stressors: an investigation of British tennis-parents. Journal of Sports Sciences, 27, 339-351.

Hein, V., \& Jõesarr, H. (2014). How perceived autonomy support from adults and peer motivational climate are related with self-determined motivation among young athletes. International Journal of Sport and Exercise Psychology. Advance online publication. doi: 10.1080/1612197X.2014.947304

Henriksen, K., \& Mortensen, J. (2014). Reality and dreams: A comparison of elite athletes' lived career paths with young talented athletes' imagined career paths. Scandinavian Sport Studies Forum, 5, 69-91.

Henriksen, K., Stambulova, N., \& Roessler, K. K. (2010a). Holistic approach to athletic talent development environments: A successful sailing milieu. Psychology of Sport and Exercise, 11, 212-222. 
Webb et al.

Henriksen, K., Stambulova, N., \& Roessler, K. K. (2010b). Successful talent development in track and field: Considering the role of environment. Scandinavian Journal of Medicine \& Science in Sports, 20(Suppl 2), 122-132.

Henriksen, K., Stambulova, N., \& Roessler, K.K. (2011). Riding the wave of an expert: A successful talent development environment in kayaking. The Sport Psychologist, 25, 341-362.

Kahneman, D., \& Klein, G. (2009). Conditions for intuitive expertise: A failure to disagree. American Psychologist, 64, 515-526.

Knowles, Z., Gilbourne, D., Borrie, A., \& Nevill, A. (2001). Developing the reflective sports coach: a study exploring the processes of reflective practice within a higher education coaching programme. Reflective Practice, 2, 185-207.

Larsen, C. H., Alfermann, D., \& Christensen, M. K. (2012). Psychosocial skills in a youth soccer academy: A holistic ecological perspective. Sport Science Review, 21, 51-74. 10.2478/v10237-012-0010-x.

Larsen, C. H., Alfermann, D., Henriksen, K., \& Christensen, M.K. (2013).Successful talent development in soccer: The characteristics of the environment. Sport, Exercise and Performance Psychology. 2, 190-206.

Martindale, R. J. J., \& Mortimer, P. (2011). Talent development environments: Key considerations for effective practice. In D. Collins, A. Button, \& H. Richards (Eds.), Performance psychology (pp. 61-77). Kidlington: Elsevier.

MacNamara, Á., Button, A., \& Collins, D. (2010a). The role of psychological characteristics in facilitating the pathway to elite performance part 1: identifying mental skills and behaviors. The Sport Psychologist, 24, 52-73. 
MacNamara, Á., Button, A., \& Collins, D. (2010b). The role of psychological characteristics in facilitating the pathway to elite performance part 2: examining environmental and stage-related differences in skills and behaviors. The Sport Psychologist, 24, 74-96.

Mageau, G. A., \& Vallerand, R. J. (2003). The coach-athlete relationship: a motivational model. Journal of Sports Sciences, 21, 883-904.

Martindale, R. J., Collins, D., \& Abraham, A. (2007). Effective talent development: the elite coach perspective in UK sport. Journal of Applied Sport Psychology, 19, 187-206.

Morris, R., Tod, D., \& Oliver, E. (2015). An analysis of organizational structure and transition outcomes in the youth-to-senior professional soccer transition. Journal of Applied Sport Psychology, 27, 216-234.

Nash, C., Martindale, R., Collins, D., \& Martindale, A. (2012). Parameterising expertise in coaching: past, present and future. Journal of Sports Sciences, 30, 985-994.

Nash, C. S., Sproule, J., \& Horton, P. (2008). Sport coaches' perceived role frames and philosophies. International Journal of Sports Science \& Coaching, 3, 538-554.

Pankhurst, A., Collins, D., \& MacNamara, Á. (2013). Talent development: linking the stakeholders to the process. Journal of Sports Sciences, 31, 4, 370-380.

Persson, T. R. (2011). Good governance and the Danish Football Association: Between international and domestic sport governance. International Journal of Sport Policy and Politics, 3, 373-384.

Petitpas, A., Champagne, D., Chartrand, J., Danish, S., \& Murphy, S. (1997). Athlete's guide to career planning. Champaign, IL: Human Kinetics. 
Webb et al.

Phillips, E., Davids, K., Renshaw, I., \& Portus, M. (2010). Expert performance in sport and the dynamics of talent development. Sports Medicine, 40, 271-283.

Potrac, P., \& Jones, R. (2009). Power, conflict and cooperation: Toward a micropolitics of head coaching. Quest, 61, 223-236.

Prochaska, J. O., DiClemente, C. C., \& Norcross, J. C. (1992). In search of how people change: Applications to addictive behaviors. American Psychologist, 47, 11021114.

Pummell, B., Harwood, C., \& Lavallee, D. (2008). Jumping to the next level: A qualitative examination of within-career transition in adolescent event riders. Psychology of Sport and Exercise, 9, 427-447.

Railo, W. (1986). Willing to win. Utrecht: Amas.

Sam, M. (2012). Targeted investments in elite sport funding: Wiser, more innovative and strategic? Managing Leisure, 17, 207-220.

Sarkar, M., Fletcher, D., \& Brown, D. J. (2015). What doesn't kill me...: Adversity related experiences are vital in the development of superior Olympic performance. Psychology of Sport and Exercise, 18, 475-479.

Schommer, M. (1990). Effects of beliefs about the nature of knowledge on comprehension. Journal of Educational Psychology, 82, 498-504.

Schommer, M. (1994). Synthesizing epistemological belief research: tentative understandings and provocative confusions. Educational Psychology Review, 6, 293-319.

Schommer-Aikins, M. (2002). Epistemological world views: A concept that is useful beyond the classroom. Issues in Education, 8(2), 229. 
Simonton, D. K. (2001). Talent development as a multidimensional, multiplicative, and dynamic process. Current Directions in Psychological Science, 10, 39-43.

Smoll, F. L., Cumming, S. P., \& Smith, R. E. (2011). Enhancing coach-parent relationships in youth sports: increasing harmony and minimizing hassle. International Journal of Sports Science \& Coaching, 6, 13-26.

Stambulova, N. (2009). Talent development in sport: A career transitions perspective. In E. Tsung-Min Hung, R. Lidor, \& D. Hackfort (Eds.), Psychology of sport excellence (pp. 63-74). Morgantown, WV: Fitness Information Technology.

Stambulova, N., Franck, A., \& Weibull, F. (2012). Assessment of the transition from junior-to-senior sports in Swedish athletes. International Journal of Sport and Exercise Psychology, 10, 79-95.

Stoszkowski, J., \& Collins, D. (2014). Communities of practice, social learning and networks: exploiting the social side of coach development. Sport, Education and Society, 19, 773-788.

Thompson, A., Potrac, P., \& Jones, R. (2013). 'I found out the hard way': micropolitical workings in professional football. Sport, Education and Society. Advance online publication, doi: 10.1080/13573322.2013.862786

Youn, I., Yang, K. M., \& Choi, I. J. (2001). An analysis of the nature of epistemological beliefs: investigating factors affecting the epistemological development of South Korean high school students. Asia Pacific Education Review, 2(1), 10-21. 
Figure 1. The straight and narrow pathway

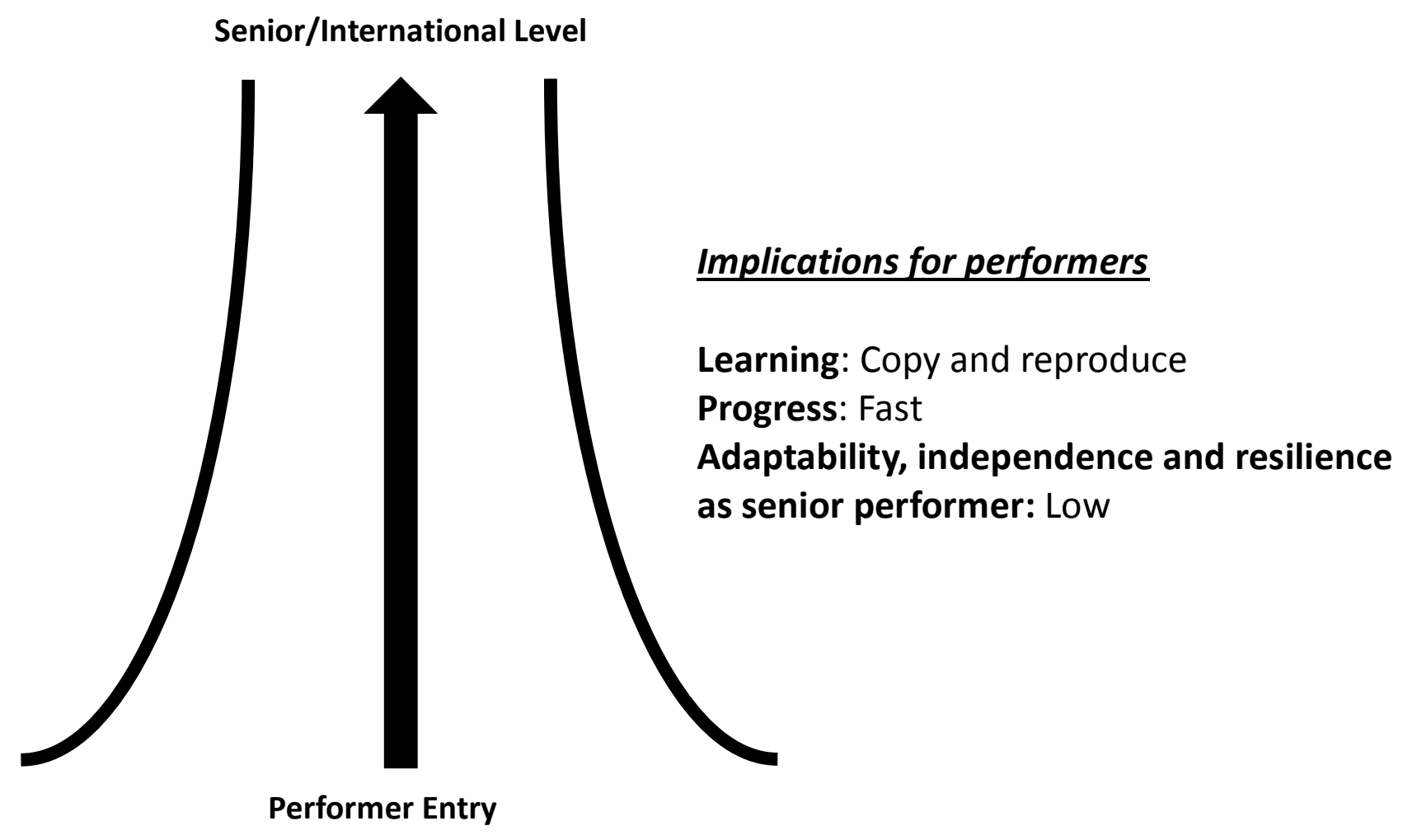


Figure 2. The long and winding pathway

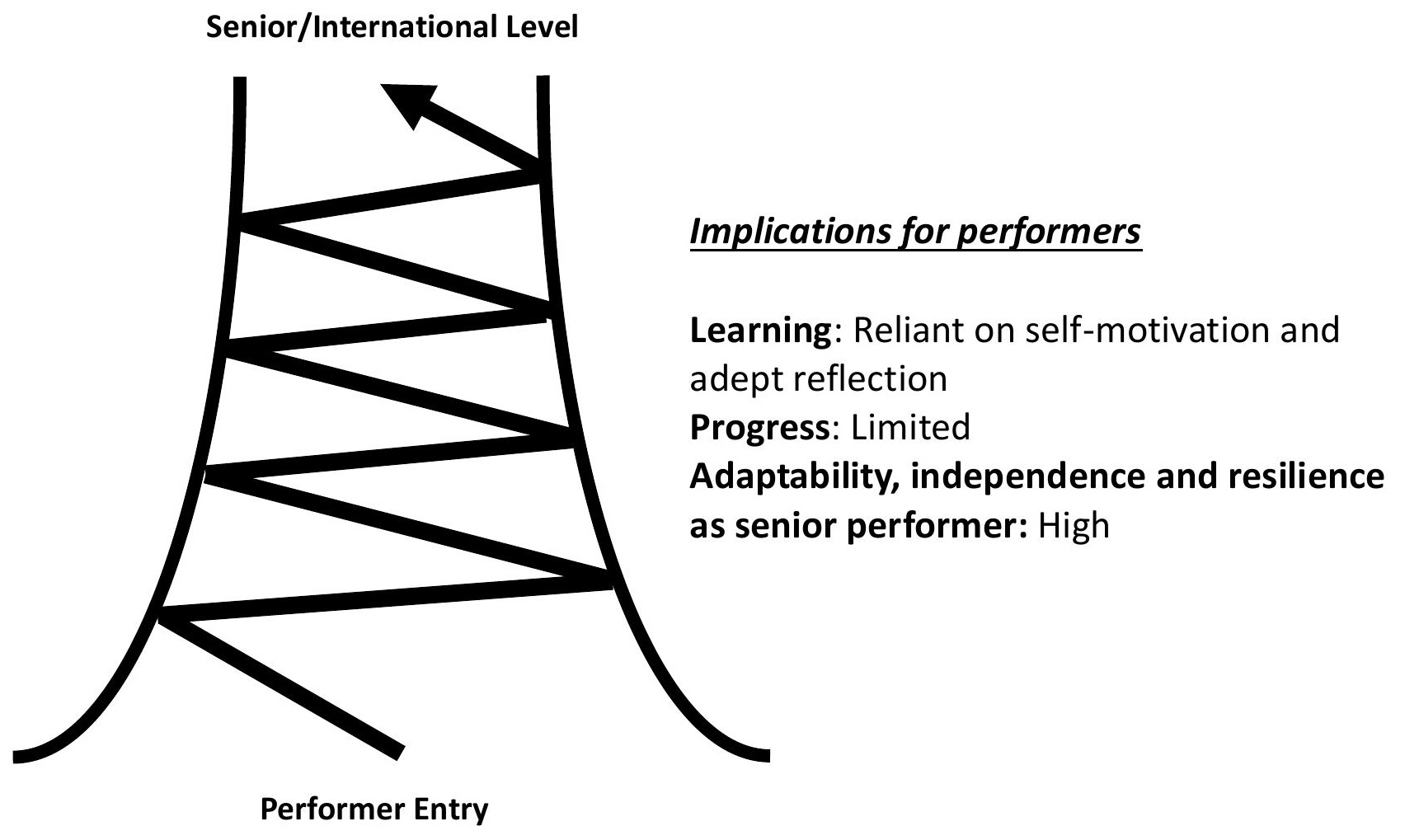


Webb et al.

Figure 3. The goldilocks pathway

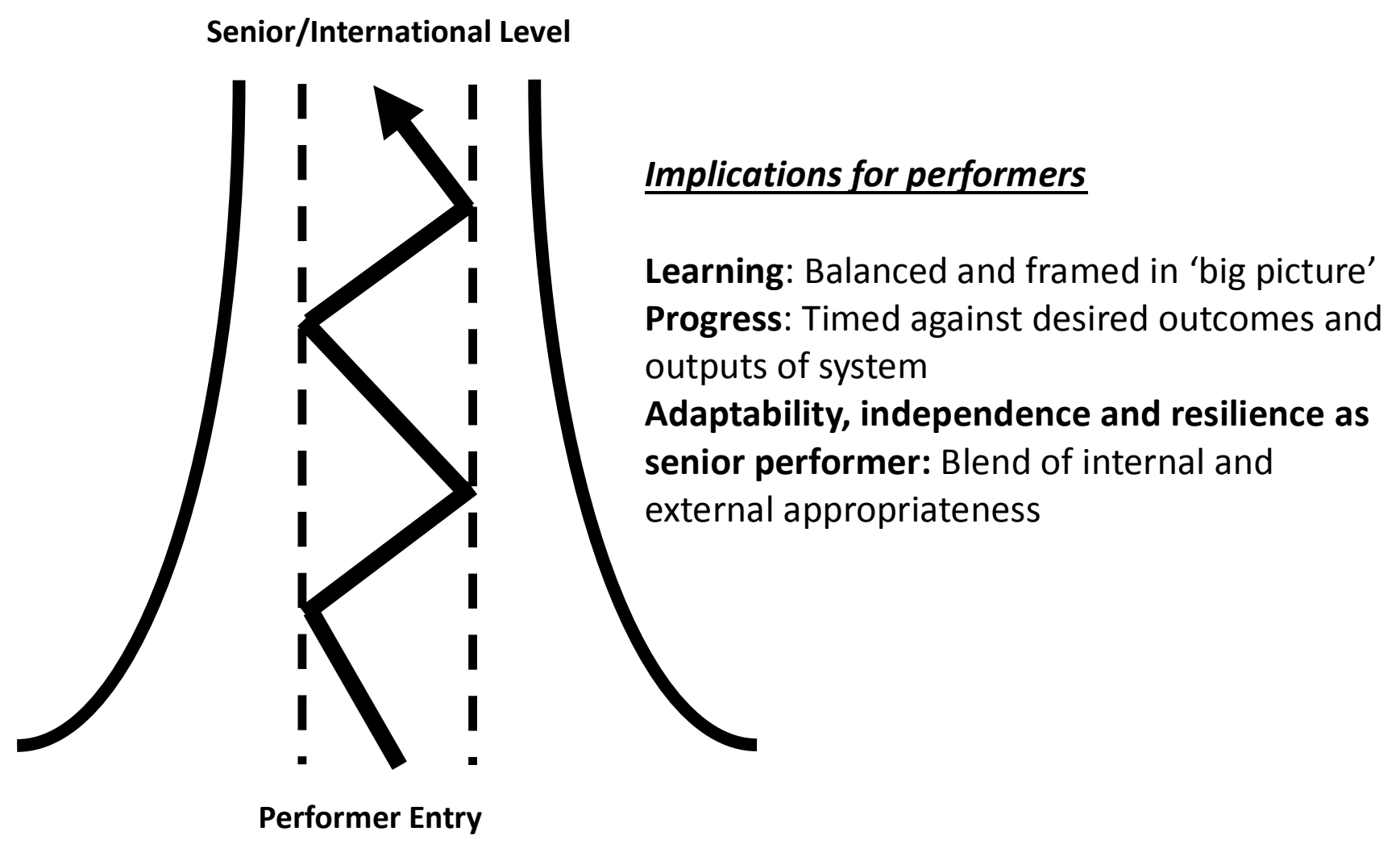


Figure 4. The incoherent pathway

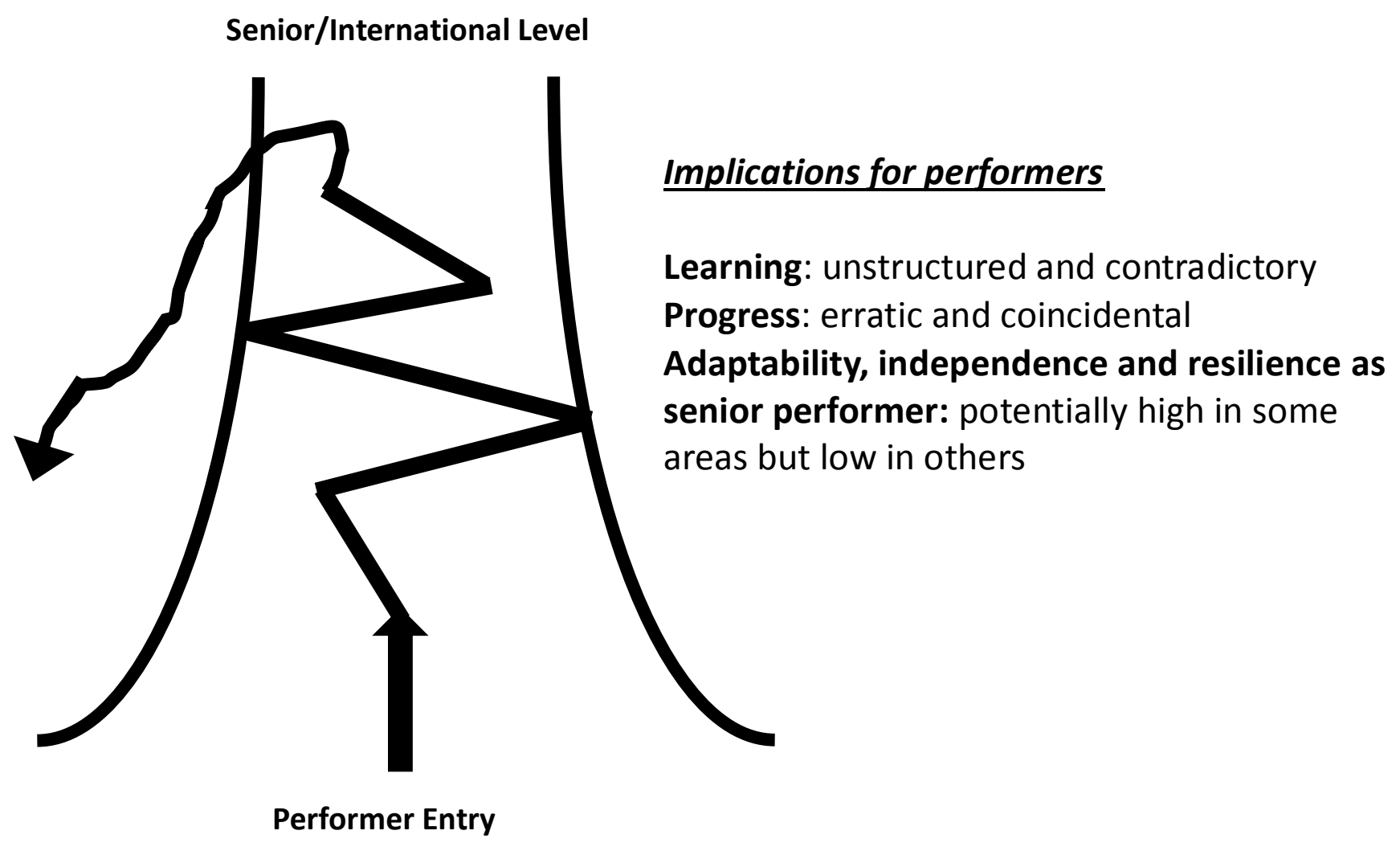


Webb et al.

Figure 5. Strategic deployment of coaches throughout the pathway - example 1

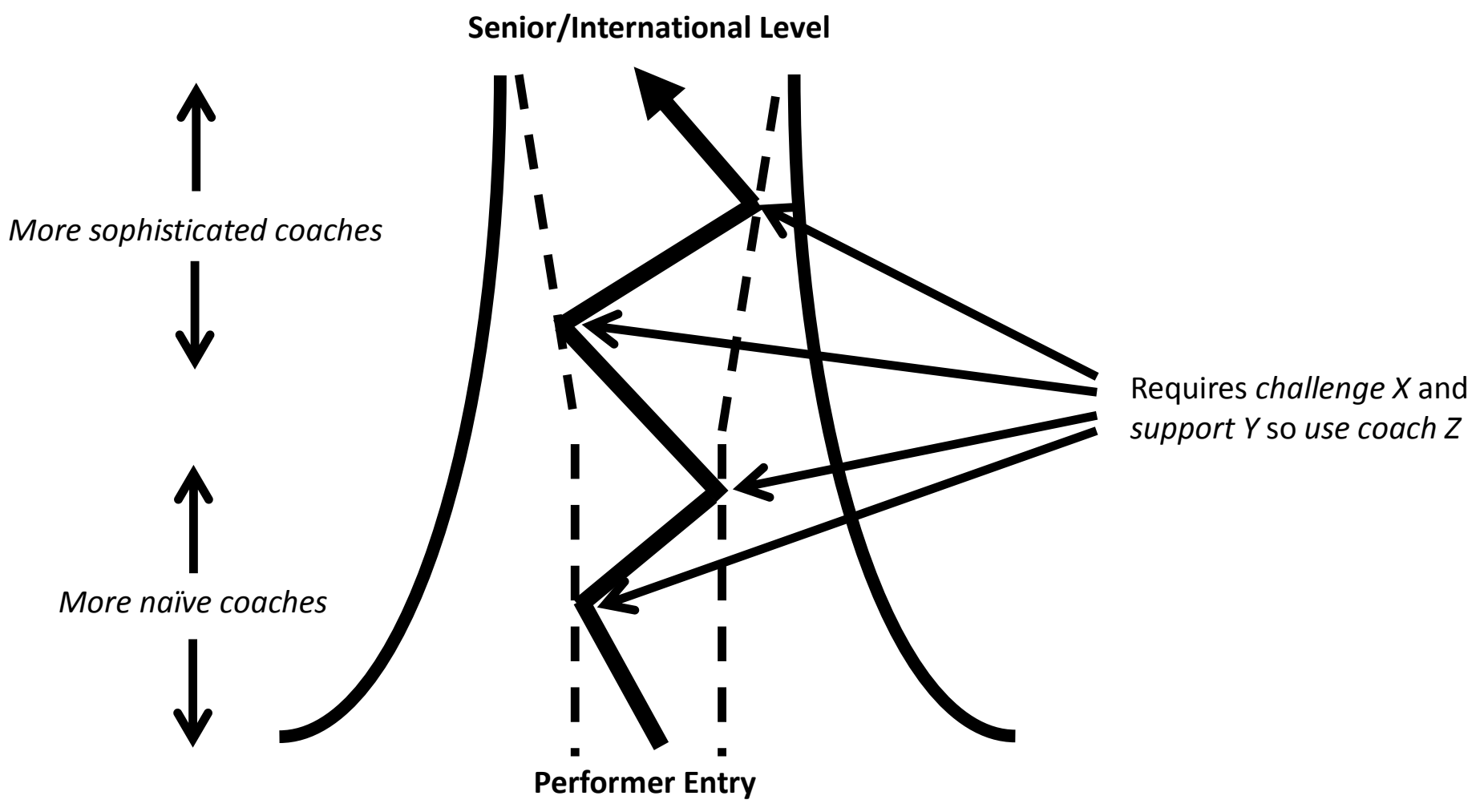


Figure 6. Strategic deployment of coaches throughout the pathway - example 2

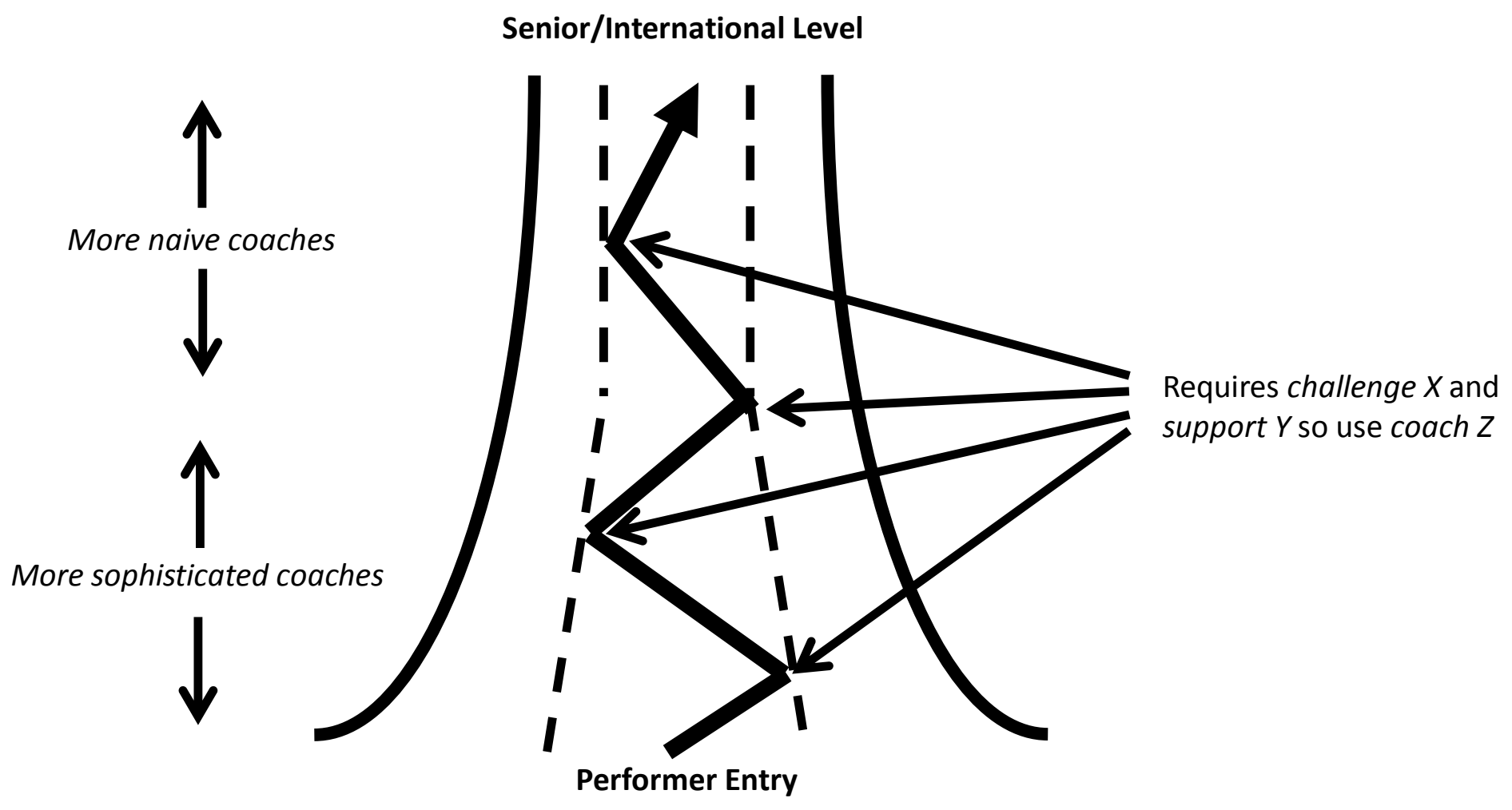

